\title{
PRELIMINARY HAZARD ANALYSIS FOR UAV-ASSISTED BRIDGE INSPECTION
}

\author{
YONAS Z. AYELE ${ }^{1} \&$ BEHROOZ ASHRAF ${ }^{2}$ \\ ${ }^{1}$ Faculty of Engineering, Østfold University College, Norway \\ ${ }^{2}$ Department of Engineering and Safety, UiT The Arctic University of Norway, Norway
}

\begin{abstract}
Unmanned aerial vehicle (UAV) technology has found its way into a number of civilian applications in the last 20 years, predominantly due to lower costs and tangible scientific improvements. In its application to structural bridge inspection, UAVs provide two main functions. The first, being the most common, detects damage through visual sensors. The 2D imagery data can be used to quickly establish a basic knowledge of the structure's condition and is usually the first port of call. The second reconstructs $3 \mathrm{D}$ models to provide a permanent record of geometry for each bridge asset, which could be used for navigation and control purposes. However, there are various problems associated with the use of UAVs for bridge inspection, in particular, in cold operating environments, such as Norway. This paper will integrate scenario prediction and assess hazards as well as the social and environmental loss in the case of UAV-assisted bridge inspection. Further, this paper will follow rather closely a threephase process: hazard identification, hazard analysis, and hazard evaluation, all executed with qualitative data and methods by experts of a variety of fields, methodologies for recognition of the impact of cold operating environment on the performance of UAVs and UAV-pilots, creative interpretation of the hazard factors of identifiable problems, or even brainstorming about "imaging the unimaginable".
\end{abstract}

Keywords: preliminary hazard analysis, UAV-assisted bridge inspection, risk assessment, drone inspection.

\section{INTRODUCTION}

Bridge infrastructures can deteriorate for a variety of factors, such as due to excessive usage, external factors (e.g., wind, earthquakes), overloading, and aging of materials; and infrastructure deterioration is often the result of a combination of these factors. This deterioration process significantly increases due to inefficient maintenance usually aggravated by technical and economic limitations associated to inspections. The issue can be categorised into two: (i) the difficulty to visually identify damage; and (ii) the late response and care of severe or irreparable damage [1], [2].

UAV technology has found its way into a number of civilian applications in the last 20 years, predominantly due to lower cost and tangible scientific improvements. In its application to structural bridge inspection, UAVs provide two main functions. The first, being the most common, detects damage through visual sensors. The 2D imagery data can be used to quickly establish a basic knowledge of the structures condition and is usually the first port of call. The second, reconstructs 3D models to provide a permanent record of geometry for each bridge asset, which could be used for navigation and control purposes. The addition of $3 \mathrm{D}$ capabilities to bridge management allows navigation through a complex structure, providing visual identification of the area of concern rather than solely relying on reference names or numbers. Models can either be constructed through photogrammetry or by assembling a spatial point cloud using laser scanners.

However, previous problems included low quality image and video capabilities, notably sensitive under poor lighting conditions and high wind speeds; (see, for example, Jung et al. [1] and Foreman et al. [3]). Further, employing UAVs for bridge inspection is still considered 
to be at an early stage from a practical point of view and a more systematic and reliable approach is needed [4]-[7]. Further, humans are "designed" to operate in very narrow temperature range and thus wind, icing and darkness reduce the operational effectiveness considerably and possibility of mistakes or being inaccurate increases during UAV-flights. In other words, the cold operational environments, which are common in northern Europe, such as Norway, have significant effect on the performance of the UAVs and UAV-pilots, and these magnify the hazards associated with the bridge inspection practices. Thus, both technical and environmental-related factors that affect the performance UAVs and UAVpilots must be recognized and quantified throughout the various phases of the bridge inspection process.

Henceforth, to fill this gap, in this paper, we integrated scenario prediction and assess hazards as well as the social and environmental impacts for UAV-assisted bridge inspection in cold operating environment. Further, this paper will follow rather closely a three-phase process: hazard identification, hazard analysis, and hazard evaluation, all executed with qualitative data and methods by experts of a variety of fields, methodologies for recognition of weak signals, creative interpretation of the hazards factors of identifiable problems, or even brainstorming about "imaging the unimaginable". The three-phase process can help to have an effective UAV-assisted bridge inspection with high level of safety in the cold operating environment.

The rest of the paper is organized as follows: Section 2 presents the preliminary hazard analysis (PHA) via a UAV-assisted bridge inspection for Grimsøy bridge, a $71.3 \mathrm{~m}$ concrete bridge, located in the Viken county in eastern Norway. Section 3 provides some concluding remarks and future work suggestions.

\section{TRADITIONAL BRIDGE INSPECTION METHODS}

Bridge inspections are conducted to identify potential changes from historical structural reports, as well to assess the current conditioning of bridge elements to ensure the asset is safe and meets service requirements. Elements are vulnerable to surface and subsurface defects, cracking and spalling with prolonged use and exposure to the natural environment. Accordingly, a record system must be established to collect and store bridge condition data from field inspections. Bridge records consist of namely two types of data: (1) inventory; (2) bridge condition data. Inventory data is identification and characteristic information such as location, functional classifications and structural type etc. Bridge condition data specifically refers to the information collected during inspections and appraisals. Here, the traditional bridge inspection techniques are summarized in Table 1.

However, the current bridge inspection and monitoring tools are not capable to coping with the ever-changing social and economic needs. Hence, there is an urgent need for reliable and efficient approaches to the inspection of bridges. One of the latest advancements in bridge inspection is employing UAVs for performing inspection in hard to reach locations and parts of any complex bridge. That means that one of the key benefits of using drones for inspection is the reduction of risks associated with current bridge inspection methods, which include - but are not limited to - rope systems and special inspection vehicles [9]. The other principal advantage is reduction of costs of bridge inspections

\section{A CASE STUDY}

In this case study we adopt a PHA for UAV-assisted bridge inspection. As such a core requirement is the identification of the hazards, which the UAV might encounter during its life cycle. In practise to achieve this during a UAV flight, the actors involved in the process 
Table 1: Traditional bridge inspection techniques - A summary.

\begin{tabular}{|l|l|}
\hline Type of inspection & Description \\
\hline $\begin{array}{l}\text { Ground-penetrating } \\
\text { radar (GPR) inspection }\end{array}$ & $\begin{array}{l}\text { GPR is one of the NDT methods, which is employed for imaging } \\
\text { the subsurface of the bridge, by using the radar pulses. }\end{array}$ \\
\hline $\begin{array}{l}\text { Acoustic or chain drag } \\
\text { inspection }\end{array}$ & $\begin{array}{l}\text { Acoustic or chain drag testing is normally used for evaluating the } \\
\text { condition bridge decks. The testing can be best achieved by } \\
\text { striking the concrete/ slab surface with hammer or in some cases } \\
\text { by dragging steel rod over the slab surface. }\end{array}$ \\
\hline $\begin{array}{l}\text { Fracture-critical } \\
\text { inspection }\end{array}$ & $\begin{array}{l}\text { The National Bridge Inspection Standards (NBIS) defined a } \\
\text { fracture-critical bridge inspection as a "hands-on" (i.e. within } \\
\text { arm's length of the component) inspection of fracture critical } \\
\text { members. }\end{array}$ \\
\hline Infrared inspection & $\begin{array}{l}\text { This method relies on changes in infrared radiation from the } \\
\text { surface of concrete that are indicative of delamination [8]. }\end{array}$ \\
\hline $\begin{array}{l}\text { Half-cell potential } \\
\text { inspection }\end{array}$ & $\begin{array}{l}\text { This inspection technique is employing for investigating the } \\
\text { corrosion of the rebar by measuring the difference of the voltage } \\
\text { between the concrete and the rebar. }\end{array}$ \\
\hline $\begin{array}{l}\text { Coring and chipping } \\
\text { inspection }\end{array}$ & $\begin{array}{l}\text { Coring - drilling a hole - and chipping - chip the cover - is a } \\
\text { technique that can be employed for checking the conditions of the } \\
\text { concrete and the rebar. }\end{array}$ \\
\hline
\end{tabular}

Table 2: Direct and indirect group actors.

\begin{tabular}{|c|c|c|}
\hline \multicolumn{2}{|c|}{ Actors } & Description \\
\hline \multirow{4}{*}{ 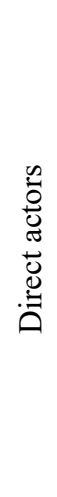 } & The bridge & $\begin{array}{l}\text { The primary unit in the process, which is the focus of the } \\
\text { inspection process }\end{array}$ \\
\hline & UAV system & $\begin{array}{l}\text { The primary inspection tool for this study and, it comprises: (i) } \\
\text { the UAV, (ii) UAV-pilot, which is the operator that flies the } \\
\text { drone or monitor it in case of autonomous operations, (iii) } \\
\text { Inspection personnel that assists the inspection process by } \\
\text { watching the live feed while the UAV is flying and gathering data }\end{array}$ \\
\hline & $\begin{array}{l}\text { Manual inspection } \\
\text { system }\end{array}$ & $\begin{array}{l}\text { Manual inspection personnel and under-bridge-inspection-truck } \\
\text { (UBIT) }\end{array}$ \\
\hline & Environment & $\begin{array}{l}\text { The environment includes: (i) Weather conditions, which is any } \\
\text { kind of disruptive weather that can halt the operations, (ii) } \\
\text { Lighting conditions: Any kind of disruptive lighting that can } \\
\text { cause problems for videos or photos that can be taken }\end{array}$ \\
\hline \multirow{6}{*}{ 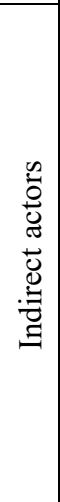 } & $\begin{array}{l}\text { Insurance } \\
\text { companies }\end{array}$ & $\begin{array}{l}\text { Insurance companies have an indirect contact with the process in } \\
\text { terms of insuring the UAV itself; and the UAV's possible } \\
\text { damages to the surrounding environment }\end{array}$ \\
\hline & $\begin{array}{l}\text { Regulatory } \\
\text { agencies }\end{array}$ & $\begin{array}{l}\text { The agencies, such as Federal Aviation Administration (FAA) of } \\
\text { the United States and, the civil aviation authority of Norway that } \\
\text { will regulate the flying of UAVs in Norway's airspace }\end{array}$ \\
\hline & Bridge users & $\begin{array}{l}\text { Anyone that uses the bridge in anyway, drivers, pedestrians, } \\
\text { bikers, etc. }\end{array}$ \\
\hline & Ships/boats & Passing boats from under the bridge \\
\hline & Birds & $\begin{array}{l}\text { Any flying birds in the vicinity of the UAV-assisted bridge } \\
\text { inspection operations }\end{array}$ \\
\hline & Others & $\begin{array}{l}\text { Any other wildlife animals in the vicinity of the operations and } \\
\text { third party intentional or unintentional involvement }\end{array}$ \\
\hline
\end{tabular}


has been identified. The actors that can affect the UAV-assisted bridge inspection, in the context of this paper, can be categorized in two different groups - direct and indirect group actors. On one hand, direct group actors are actors that have a direct physical contact with the inspection process. On the other hand, the indirect group actors are the actors, which have indirect effects on the UAV-assisted bridge inspection process. The direct and indirect actors are summarized in Table 2.

\subsection{Grimsøy bridge, Norway}

The following case study describe the investigative methods and results for hazard analysis, when employing UAVs for bridges inspections in cold operating environment. The location, structure description, access methods, investigation methods, site specific safety analysis and imagery results are discussed for the bridge.

Grimsøy bridge ensures road connection out to Grimsøy, which is a peninsula in Skjeberg, Østfold Region, Norway. It is situated at latitude: $59.1355^{\circ}$ or $59^{\circ} 8^{\prime} 7.7^{\prime \prime}$ north and longitude: $11.2011^{\circ}$ or $11^{\circ} 12^{\prime} 3.9^{\prime \prime}$ east, and with elevation: $15 \mathrm{~m}(49 \mathrm{ft})$. The bridge is a concrete slab bridge with concrete pillars in the relatively shallow water. The bridge is constructed in typical coastal landscape, but lies in a wedge without exposure to the sea. On Grimsøy, the character of the landscape is dominated by vegetation and sloping terrain/mountains down to the sea. Fig. 1 illustrates an overall view and location and structure description of Grimsøy bridge.

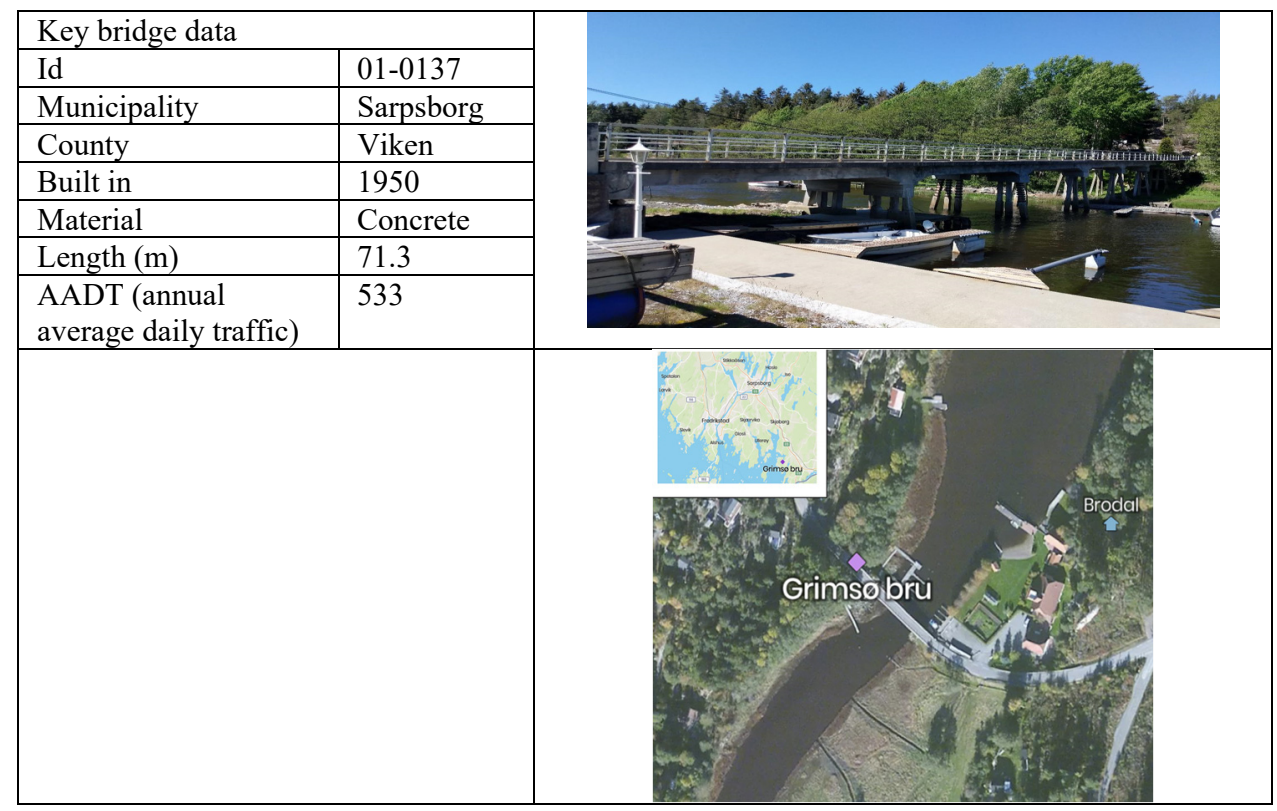

Figure 1: Overall view and location and structure description of Grimsøy bridge.

Before going out to the field, we did make sure that the onsite risk assessment has been carried out and the checklist for UAV operations is ready. The following tools and equipment are used during UAV-based inspection (Fig. 2): UAVs (DJI Matrice 100 and Phantom 4 Pro 

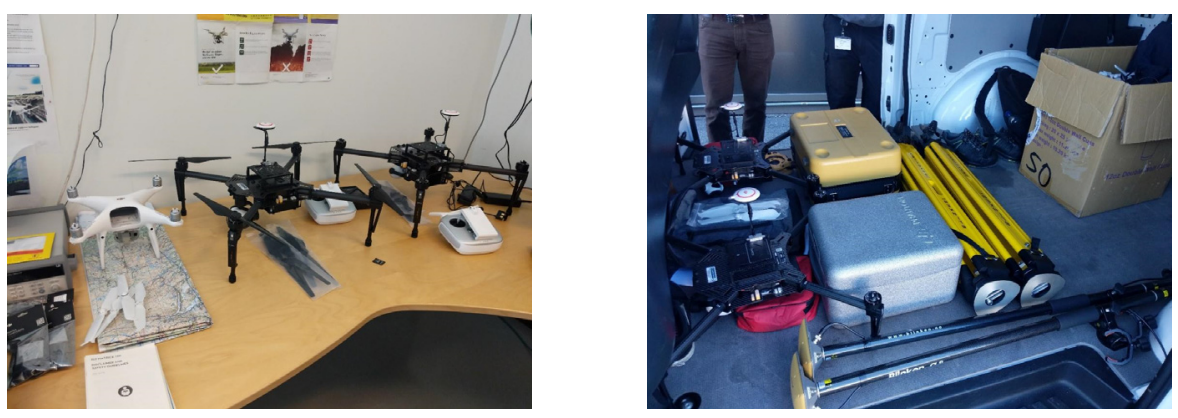

Figure 2: DJI Matrice 100 and other equipment used for UAV-assisted inspection.

V2.0) and remote controllers, landing platform, Zenmuse Z3 camera (an integrated aerial zoom camera with $7 \mathrm{X}$ zoom capacity), GPS antenna and handheld, total station, tripods, spare batteries, blades, iPad and connection wires to drone remotes, helmets, safety boots and reflective jackets, tapes and markers.

Once done with onsite risk assessment, we have commenced UAV-assisted bridge inspection. Reasonably slow-moving vehicles and so it was easier to work alongside the bridge. No issues with traffic control/safety. There were some trees towards the far end of the bridge but not too obtrusive for the UAV operation. However, there was space next to the bridge for parking and UAV take-off/landing with good line of sight across the bridge. Total station was set at the far end of the bridge with the GPS antenna in line of sight at the near end next to the drone-pad. Markers placed along the bridge for both total station recordings and GPS - used white tape with markings. After all the set-up both the total station and GPS equipment, so recordings were started. The first flight of the UAV went well with photos taken from top and oblique angles. The UAV operation needed two people - one for controlling the UAV and the other to taking the photos. During our first flight, we took hundreds of photos in different angles and overlap. Fig. 3 below show the level of details obtained from the UAV based imaging for Grimsøy bridge.

\subsection{Hazard identification}

When identifying and categorizing hazards, a reasonable effort has been made to identify those that will have the most significant implications on the strategic decision. Further, it is important to note that a "hazard" only represents a potential to cause harm. Whether it actually does causes harm will depend on circumstances, such as the type of the hazard, flight duration, etc. Hazards can also be rated according to the severity of the harm they cause - a significant hazard being one with the potential to cause a catastrophic, which is a very high or severe damage. Identifying hazards in the UAV-assisted bridge inspection involves finding things and situations that could potentially cause harm to people involved, the UAV system, etc. Hazards, during the UAV-assisted inspection generally arise from the following aspects of work and their interaction: physical work environment; equipment and materials used; inspection tasks and how they are performed; and bridge inspection design and management of UAVs.

Further, when assessing hazards associated with the UAV-assisted inspection in cold regions, including Norway, the effect of the operating environment needs to be analysed thoroughly. This is due to the fact that the operating environment is one of the dominant 


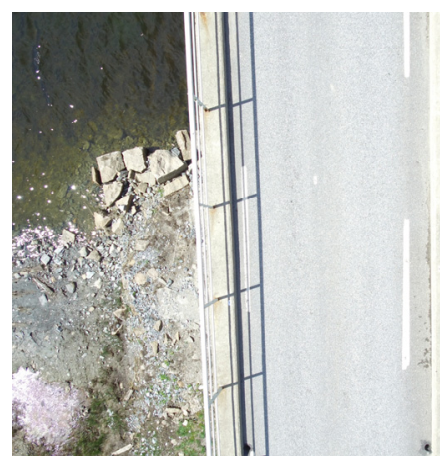

(a)

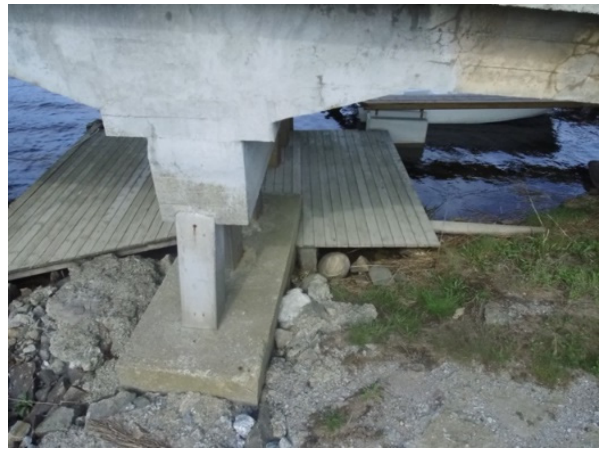

(c)

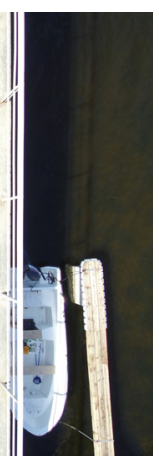

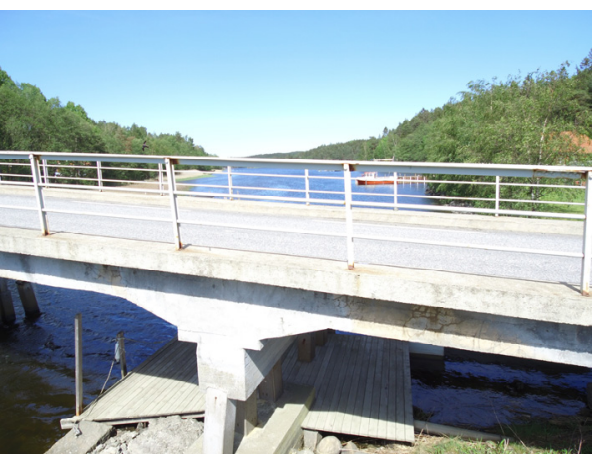

(b)

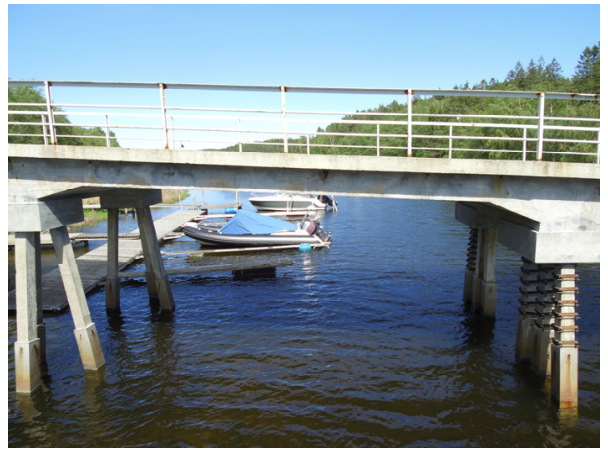

(d)

Figure 3: Level of details obtained from the UAV-assisted imaging for Grimsøy bridge. (a) Grimsøy bridge top view; (b) UAV image of Grimsøy bridge near top deck; (c) UAV image of Grimsøy bridge near foundation; and (d) UAV image of Grimsøy bridge showing bridge columns and supports.

factors, which influences the performance of the inspectors, the function of UAVs, and then consequently increases the hazards. Table 3 lists some common types of hazards associated with UAV-assisted inspection in cold operating environment. These hazards identified comprises both UAV-assisted nature of the bridge inspection and, the fact that these inspections are being conducted in cold regions, such as Norway.

\subsection{Defining the scales for probability and consequence}

For defining the consequence scale criteria, there is a need to define the systems mission. The systems mission can be defined as the ability of the UAV to carry on visual inspection of any bridge in cold operating environment in a certain time and within a certain standard. The success and failure of the mission can be defined as follows:

- Mission success: UAV can complete the mission and gather the required data within the acceptable standards and return to base intact.

- Mission failure: UAV cannot fulfil the minimum data required for inspection process or the UAV is destroyed during the mission. 
For defining the scale for the probability, the conventional probability ranking is adapted and is shown in Table 4. The consequence scale based on the mission success and failure is depicted in Table 5.

Table 3: Identified hazards.

\begin{tabular}{|c|c|c|}
\hline ID & Hazards $(\mathrm{H})$ & Description and potential consequences \\
\hline $\mathrm{H}-1$ & $\begin{array}{l}\text { Low } \\
\text { temperatures }\end{array}$ & $\begin{array}{l}\text { - Creates a problem for the endurance of the UAVs and will possibly } \\
\text { decrease the battery life of the UAV. } \\
\text { - Performance decrements of UAV-pilots due to cold hands, cold muscles } \\
\text { or general cooling or due to hinders caused by protective clothing against } \\
\text { cold such as weight, bulk, friction, etc. } \\
\text { - Lack of concentration, due cold environment, during UAV-assisted } \\
\text { bridge inspection can causes fatal accidents. }\end{array}$ \\
\hline $\mathrm{H}-2$ & $\begin{array}{l}\text { Ice and } \\
\text { snow } \\
\text { accretion }\end{array}$ & $\begin{array}{l}\text { - Ice and snow accretion on the body of the UAVs; and this causes } \\
\text { problems for the rotary blades, loss of control of the UAV, degraded } \\
\text { performance of the UAV, and instrument and sensor malfunctions. }\end{array}$ \\
\hline $\mathrm{H}-3$ & Darkness & $\begin{array}{l}\text { - Insufficient visibility due to darkness increases the hazards during the } \\
\text { UAV-assisted bridge inspection } \\
\text { - It can have effects on vision and target detection of the UAV and, it can } \\
\text { degrade the operator's performance. }\end{array}$ \\
\hline H-4 & High winds & $\begin{array}{l}\text { - Wind is a common hazard in most parts of Norway, especially on bridges } \\
\text { which are in contact with the sea or rivers and open areas the probability } \\
\text { of high winds is much higher. } \\
\text { - It can cause loss of control during landing and navigation of the UAV. It } \\
\text { also can degrade the UAV operator's performance. }\end{array}$ \\
\hline H-5 & $\begin{array}{l}\text { Lack of } \\
\text { experience }\end{array}$ & $\begin{array}{l}\text { - Using UAVs for inspection purposes is a relatively new field all over the } \\
\text { world, and Norway is no exception in this matter. In addition, the special } \\
\text { operating conditions in Norway, such as darkness, abrupt weather, high } \\
\text { winds, etc. will require more experienced UAV pilots. This hazard has } \\
\text { no direct effects on the system; however, it can cause systematic } \\
\text { problems when other hazards are in play. For example, in case of any } \\
\text { disturbance in the system the pilot won't have enough experience dealing } \\
\text { with the problems that are unique in Norway and It can lead to accidents. }\end{array}$ \\
\hline H-6 & $\begin{array}{l}\text { GPS } \\
\text { malfunctions }\end{array}$ & $\begin{array}{l}\text { - GPS malfunction is a common error in UAVs operations, in particular in } \\
\text { under bridge inspection processes the loss of GPS signal in these areas is } \\
\text { a common error. }\end{array}$ \\
\hline $\mathrm{H}-7$ & $\begin{array}{l}\text { Infrared } \\
\text { sensor } \\
\text { malfunctions }\end{array}$ & $\begin{array}{l}\text { - Infrared sensor malfunction is another hazard, which is common. This } \\
\text { hazard can lead to problems in collision avoidance systems. }\end{array}$ \\
\hline $\mathrm{H}-8$ & $\begin{array}{l}\text { Ground } \\
\text { control } \\
\text { hazards }\end{array}$ & $\begin{array}{l}\text { - Human operators' error: In this case the human operator's error will be } \\
\text { related to UAV pilots' skills in controlling the UAV, especially since in } \\
\text { the UAV-based inspection, the UAV is flying close to some parts of the } \\
\text { bridge, small mistakes combined with a little of wind can lead to } \\
\text { collision. } \\
\text { - Software malfunction: The UAV usually operate based on a software in } \\
\text { the control device, there are possibilities that this software run into } \\
\text { various types of problems and, the UAV pilot will be unable to control } \\
\text { the UAV properly. } \\
\text { - Hardware malfunction or controller physical malfunction: The UAV } \\
\text { control device can run into physical problems such as interface lack of } \\
\text { response, internal part failure etc., which makes the pilots run into } \\
\text { problems while controlling the UAV. }\end{array}$ \\
\hline
\end{tabular}


Table 3: Continued.

\begin{tabular}{|c|c|c|}
\hline ID & Hazards $(\mathrm{H})$ & Description and potential consequences \\
\hline H-9 & $\begin{array}{l}\text { Collision } \\
\text { avoidance } \\
\text { malfunction }\end{array}$ & $\begin{array}{l}\text { - Due to the nature of the inspection process the UAV needs to fly } \\
\text { close to the bridge structure, and although the collision avoidance } \\
\text { systems have a small margin of error, there is the possibility of } \\
\text { malfunction that can lead to collision. This hazard is talking about } \\
\text { the algorithms and systems embedded in the UAV for collision } \\
\text { avoidance. In case of malfunction in any of these algorithms or } \\
\text { systems, UAV can have problems in navigation, and this can lead to } \\
\text { accidents. }\end{array}$ \\
\hline $\mathrm{H}-10$ & $\begin{array}{l}\text { UAV is unable to } \\
\text { collect } \\
\text { information about } \\
\text { the quality of } \\
\text { internal materials }\end{array}$ & $\begin{array}{l}\text { - UAVs can't be used to gather data on the internal material quality } \\
\text { by visual sensing techniques alone. }\end{array}$ \\
\hline $\mathrm{H}-11$ & $\begin{array}{l}\text { Possible } \\
\text { disruption for the } \\
\text { passing } \\
\text { ships/boats from } \\
\text { under the bridge }\end{array}$ & $\begin{array}{l}\text { - A significant number of bridges in Norway connect two islands, } \\
\text { which makes it essential for ships/boats to pass beneath the bridge, } \\
\text { this can cause hazards of collision between ships/boat and UAVs } \\
\text { during under-bridge inspections. With the ships/boats passing } \\
\text { beneath the bridge, there is the possibility of UAV falling down and } \\
\text { hit the ships/boats. The other case could be debris falling off due to } \\
\text { the near collision or collision of the UAV with bridge structure } \\
\text { which can lead to hazards for both the personnel on the boat and the } \\
\text { boat itself specially in under bridge inspection scenarios. }\end{array}$ \\
\hline H-12 & $\begin{array}{l}\text { Visual camera } \\
\text { malfunction }\end{array}$ & $\begin{array}{l}\text { - For UAV-assisted bridge inspection, the visual camera mounted on } \\
\text { the UAV needs to be operational and available at all times, in case } \\
\text { of any malfunctions in this part of the UAV the mission cannot be } \\
\text { completed. This hazard can lead to mission failure, due to inability } \\
\text { of taking pictures and video. Further, if it paired up with other } \\
\text { sensors malfunction it can lead to UAV colliding with the bridge } \\
\text { structure or personnel. }\end{array}$ \\
\hline $\mathrm{H}-13$ & Bird attack & $\begin{array}{l}\text { There is a possibility of birds attacking or colliding with the UAV, } \\
\text { especially in the summer with the vast number of seagulls roaming } \\
\text { in the skies of Norway. Seagulls are aggressive in nature; they } \\
\text { might attack or collide with the UAV. }\end{array}$ \\
\hline H-14 & Noise & $\begin{array}{l}\text { - The noise generated by the quadrotor's blades can be a hazard for } \\
\text { the wildlife. }\end{array}$ \\
\hline H-15 & $\begin{array}{l}\text { Disruptions of } \\
\text { vision due to } \\
\text { direct sun }\end{array}$ & $\begin{array}{l}\text { - During the midnight sun period specially in northern Norway, direct } \\
\text { sunlight can disrupt the vision of both operators and the camera of } \\
\text { the UAV. This can lead to both low quality imaging, and in worst } \\
\text { scenarios it can lead to accidents due to lack of vision. }\end{array}$ \\
\hline H-16 & $\begin{array}{l}\text { Disruption of } \\
\text { wireless signals }\end{array}$ & $\begin{array}{l}\text { - The wireless link between the ground control and the UAV may be } \\
\text { jammed or blocked by intentional/unintentional use of transmitting } \\
\text { devices that are operating on the same frequency band, which can } \\
\text { lead to loss of signal and the UAV pilot will not be able to control } \\
\text { the UAV. }\end{array}$ \\
\hline $\mathrm{H}-17$ & Rain & $\begin{array}{l}\text { - Heavy rain conditions can cause hazards for the UAVs. Rain, which } \\
\text { is a normal phenomenon in most of Norway, can cause hazards for } \\
\text { the UAVs, for example, it can lead to sensor malfunction, and also } \\
\text { it can disrupt the image quality, in case of heavy rain the possibility } \\
\text { of navigation difficulties and loss of control is also present. }\end{array}$ \\
\hline
\end{tabular}


Table 4: Probability ranking.

\begin{tabular}{|l|l|l|}
\hline Probability & Description & Definition \\
\hline 1 & Very unlikely, rare probability & Negligible, insignificant consequences \\
\hline 2 & Unlikely, possible but not likely & Slight, minor consequences \\
\hline 3 & $\begin{array}{l}\text { Possible, can occur once in } \\
1,000 \text { flights }\end{array}$ & Moderate \\
\hline 4 & $\begin{array}{l}\text { Likely, anticipated few times in } \\
1,000 \text { flights }\end{array}$ & Major, cause high or significant impact \\
\hline 5 & Very likely, almost certain & $\begin{array}{l}\text { Catastrophic, very high or severe } \\
\text { damage }\end{array}$ \\
\hline
\end{tabular}

\subsection{Hazard assessment via PHA based on expert judgment}

The basic assumptions in this PHA are: a year-round UAV operational window and the fact that the UAV-assited inspection is carried out in Norway. Since employing UAV for bridge inspection is relatively new, there is a lack of historical UAV system failure rate data. Hence, judgements provided by those people with expertise in identifying potential hazards and risks of undesirable events are utilised at various stages of this hazard analysis in order to perform effective hazard identification and quantification. Their expertise is used to analyse historical information, define and analyse potential hazards, and evaluate the consequence of undesirable events.

- $\quad$ Selecting the experts: In this PHA we have employed a criteria suggested by Ortiz et al. [10] regarding how to select experts. The chosen experts are categorised into two, namely academics and specialists with hands-on skills on UAV flights, know-how in hazards assessment, bridge inspection, meteorology, cold- and climate technology, with 5 to 15 years of experience in their respective fields.

- Posing questions to the experts: In order to facilitate the PHA, the surveys are set by reciting the likely hazards and unwanted events. The hazards are proposed for use as guidance, and consequence (safety, economic, and environmental consequences) categories are also postulated.

- $\quad$ The quality of the expert judgements: Hora [11] have pointed out that degree-of-belief probabilities are personal. In addtion, these probabilities differ from expert to expert and from time to time. This leads us there is no "true" probability that one might use as a measure of the accurateness of a single elicited probability. For depicting such kinds of distortion, we employed the weighted distributions approach for each degree-of-belief probabilities. Thereafter, we have requested the experts to specify 5\% (lower), $50 \%$ (median) and 95\% (upper) values for the potential hazards probabilities. The results show that some of the experts can be regarded as over-confident and biased; and on the other hand, some of the experts are well calibrated but uninformative; the last group regarded as well calibrated and informative. Henceforth, it is apparent that we should have a procedure for calibration for experts. Hora [11] put calibration prosess as "faithfulness of probabilities in that events that are assigned a probability $p$ should occur with a relative frequency of $p$ ". Thus, for crosschecking the goodness of the probabilities, these two properties are necessary [11]: $i$ ) degree-of-belief probabilities should be informative, and ii) degree-of-belief probabilities should authentically represent uncertainity. 


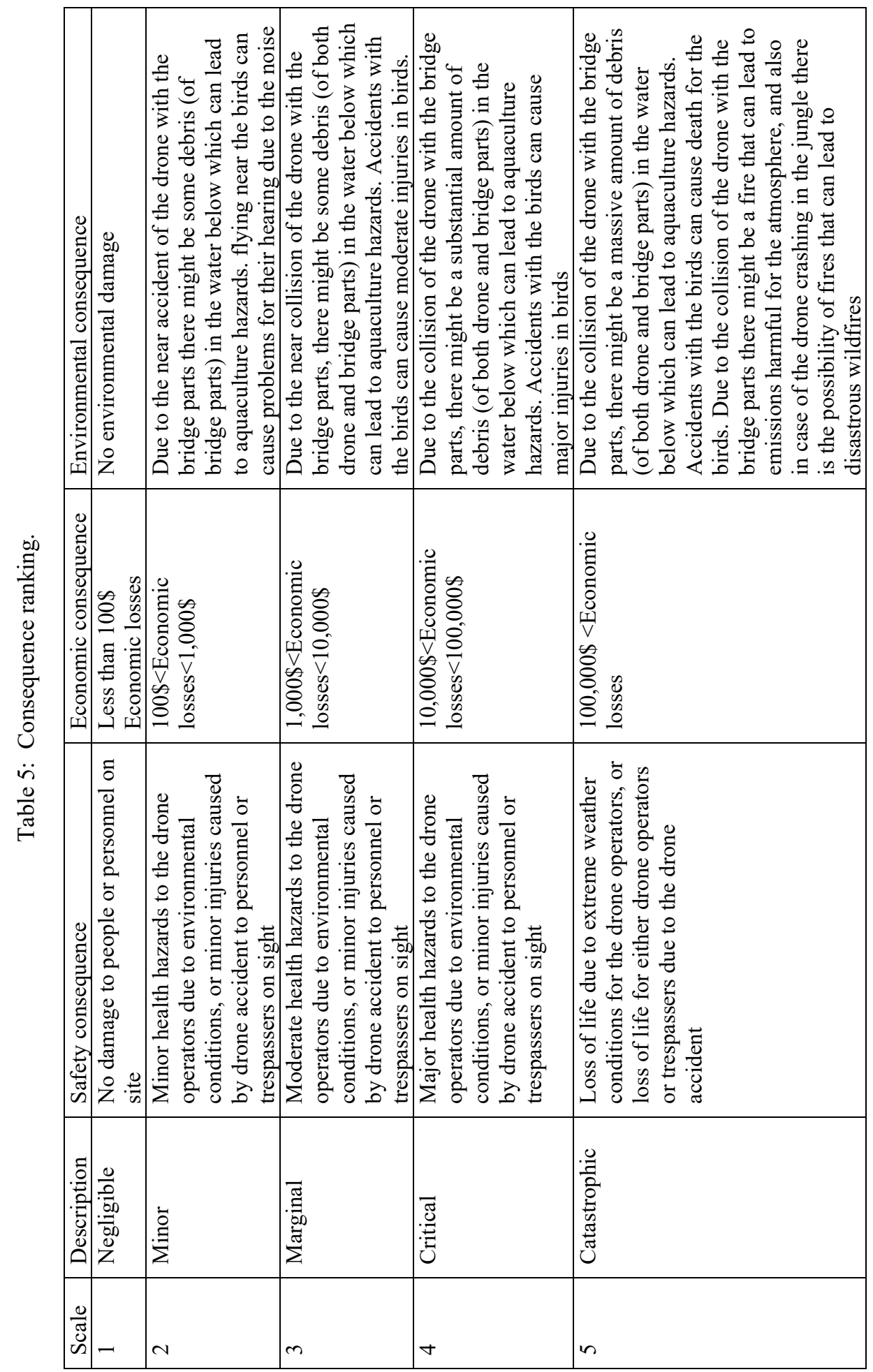




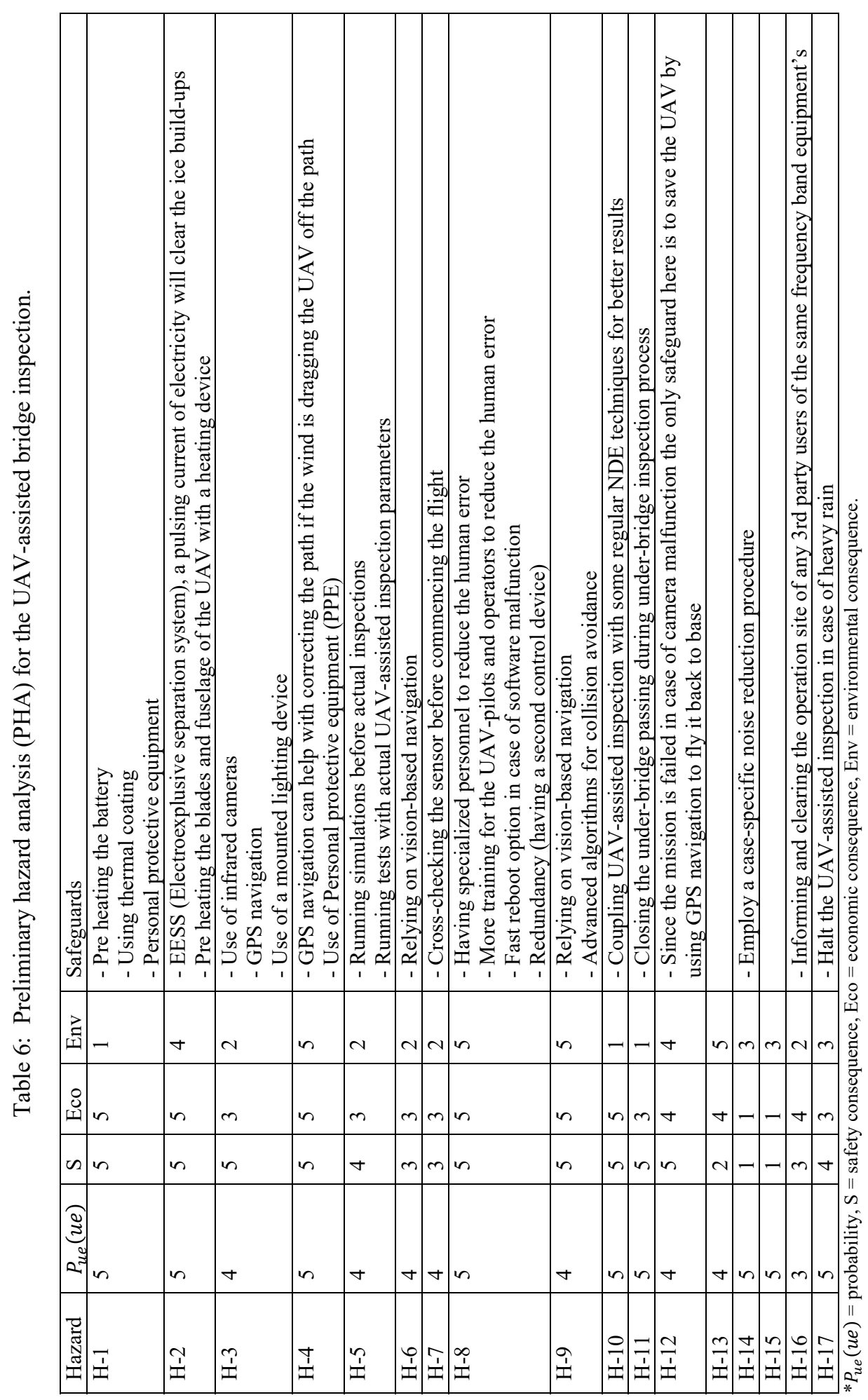


In addition to calibiration, one can emply the concept of convergence, for validating judgement results. In simple terms, as per Chang et al. [12], convergence, can be realised by soliciting the same fundamental question in several different ways. Henceforth, for fulfuling the above two properties and evaluate the quality of experts' judgements, we have calibirated the degree-of-belief probabilities.

Subsequently, two scores - calibration and information - have been employed for esimating the non-normalised performance-based weight for each expert $i$. In this PHA, experts are scored on the basis of answers to questions for which the answer is only known to the analyst. The non-normalised performance-based weight for expert $i$, can be defined as follows, based on Cooke [13] and Ayele et al. [14]

$$
k_{n n w_{i}} \propto C\left(E_{i}\right) \times I\left(E_{i}\right),
$$

where:

$k_{n n w_{i}}$ is the non-normalised performance-based weight for expert $i$;

$C\left(E_{i}\right)$, represents the calibration score for expert $i$;

$I\left(E_{i}\right)$, represents the information score for expert $i$.

- Aggregating the expert judgements: We have employed an expert aggregation method is used, for combining the elicited probabilities, based on Cooke [13] and Ayele et al. [14]:

$$
P_{u e}(u e)=\sum_{i=1}^{n} k_{n w_{i}} P_{u e_{i}}\left(u e_{i}\right)
$$

where:

$P_{u e}(u e)$ is the aggregated expert judgement probability of unwanted event;

$k_{n w_{i}}$ is the normalised performance-based weight for expert $i$ and is expressed as:

$$
k_{n w_{i}}=\frac{k_{n n w_{i}}}{\sum_{i=1}^{n} k_{n n w_{i}}}
$$

Thereafter, for each actors relations with the hazards, the aggregated values, by considering the normalised experts' performance-based weight, are assessed and conferred in Table 6.

\section{RESULT DISCUSSION AND CONCLUDING REMARKS}

UAV deployment in bridge inspection could potentially save time and money. However, it also has various shortcomings. We have conducted a PHA for understanding the hazards exists in the use of UAVs in bridge inspections and for future inspection planning. Further, employing PHA can be beneficial to recognize and quantify technical and cold environmental factors affecting pilot performance throughout the various phases of the bridge inspection. The conducted PHA concentrates on the technical related hazards as well as the effects of cold and harsh environments on the reliability of human performance i.e. the UAV-pilot performance, recognizing that human actions are influenced by the cold environment.

The findings are:

- From the conducted PHA, we can deduce that:

- Low Temperature: Creates a problem for the endurance of the UAVs and will decrease the battery life of the UAV. Further, it causes a significant performance decrements of UAV-pilots due to cold hands, cold muscles or general cooling or due to hinders caused by protective clothing against cold such as weight, bulk, 
friction, etc. In addition, lack of concentration, due cold environment, during UAVassisted bridge inspection can instigates fatal accidents.

- Ice and Snow Accretion: Ice and snow accretion on the body of the UAVs; and this causes problems for the rotary blades, loss of control of the UAV, degraded performance of the UAV, and instrument and sensor malfunctions.

- Darkness: Insufficient visibility due to darkness increases the hazards during the UAV-assisted bridge inspection. It can have effects on vision and target detection of the UAV and, it can degrade the operator's performance.

- From the PHA analysis, we can also infer that the safety consequence of the hazards such as: Wind Hazard, Ground Control Hazard, Collision Avoidance Malfunction, Visual Camera Malfunction is regarded as catasrophic, which means that they might cause losses of life due to the extreme wind conditions for the UAV operators, or loss of life for either UAV operators or trespassers due to the UAV accident due to malfunction. The associated economic consequence could also might be well above US\$100,000 in some cases.

Our intent is not to provide generalized advice on whether UAV-assisted bridge inspection should replace the conventional inspection or not, since these prescriptions will be particular to and heterogeneous to types of bridges and accompanied UAVs rules and regulations. Rather, the intent is to highlight the fact that even if UAV-assisted bridge inspection has a huge potential in the years to come, the associated hazard has to be investigated thoroughly. This will assist the decision maker to identify the most cost-effective and efficient bridge inspection procedures with minimum level of HSE-C (health, safety, and environment, and cost) risk.

\section{ACKNOWLEDGEMENTS}

The work has been partially funded by The Regionale Forskningsfond Oslofjordsfondet Norway through the safeBRIDGE project - Development of Models and Algorithms for Resilience Assessment of Bridges based on Monitoring, Diagnosis and Prognosis of Damage via the use and Integration of Vibration Signals and UAV (drone) - based image segmentation facilitated at Østfold University College. The financial support was gratefully acknowledged.

\section{REFERENCES}

[1] Jung, H.-J., Lee, J.-H. \& Kim, I.-H., Challenging issues and solutions of bridge inspection technology using unmanned aerial vehicles. Sensors and Smart Structures Technologies for Civil, Mechanical, and Aerospace Systems 2018, 10598, p. 1059802, 2018.

[2] Ayele, Y.Z. \& Droguett, E.L., Application of UAVs for bridge inspection and resilience assessment. 29th European Safety and Reliability Conference, Hanover, Germany, 2019. DOI: 10.3850/978-981-11-2724-3 0954-cd.

[3] Foreman, V.L., Favaró, F.M., Saleh, J.H. \& Johnson, C.W., Software in military aviation and drone mishaps: Analysis and recommendations for the investigation process. Reliability Engineering and System Safety, 137, pp. 101-111, 2015.

[4] Rakha, T. \& Gorodetsky, A., Review of unmanned aerial system (UAS) applications in the built environment: Towards automated building inspection procedures using drones. Automation in Construction, 93, pp. 252-264, 2018. 
[5] Ciampa, E., De Vito, L. \& Pecce, M.R., Practical issues on the use of drones for construction inspections. Journal of Physics: Conference Series, 1249(1), p. 012016, 2019.

[6] Seo, J., Wacker, J.P. \& Duque, L., Evaluating the use of drones for timber bridge inspection, General Technical Report FPL-GTR-258, US Department of Agriculture, Forest Service, Forest Products Laboratory: Madison, WI, 258, pp. 1-152, 2018.

[7] Ayele, Y.Z., Drones for inspecting aging bridges. Presented at the International Conference on Natural Hazards and Infrastructure, Chania, Crete, 23-26 Jun. 2019.

[8] Roberts, R., Inside the bridge inspection toolbox. www.structuremag.org/?p=8064. Accessed 21 Jan. 2019.

[9] Wells, J. \& Lovelace, B., Improving the quality of bridge inspections using unmanned aircraft systems (UAS), 2018.

[10] Ortiz, N., Wheeler, T., Breeding, R., Hora, S., Meyer, M. \& Keeney, R., Use of expert judgment in NUREG-1150. Nuclear Engineering and Design, 126(3), pp. 313-331, 1991.

[11] Hora, S.C., Expert Judgement in Risk Analysis, 2009.

[12] Chang, S.E., McDaniels, T., Fox, J., Dhariwal, R. \& Longstaff, H., Toward disasterresilient cities: Characterizing resilience of infrastructure systems with expert judgments. Risk Analysis, 34(3), pp. 416-434, 2014.

[13] Cooke, R.M., Experts in Uncertainty: Opinion and Subjective Probability in Science, 1991.

[14] Ayele, Y., Barabadi, A. \& Droguett, E., Risk-based cost-effectiveness analysis of waste handling practices in the arctic drilling operation. Journal of Offshore Mechanics and Arctic Engineering, 138(3), 2016. 